\title{
Alterations in cell death and cell cycle progression in the UV-irradiated epidermis of bcl-2-deficient mice
}

\author{
Frank Gillardon ${ }^{1,4}$, Ingrid Moll ${ }^{2}$, Michael Meyer ${ }^{3}$ and \\ Theologos M. Michaelidis ${ }^{3}$

\footnotetext{
1 II. Physiologisches Institut, Universität Heidelberg, Heidelberg, Germany

2 Hautklinik, Mannheim, Germany

${ }^{3}$ Max-Planck-Institut für Neurobiologie, Martinsried, Germany

${ }^{4}$ corresponding author: Boehringer Ingelheim Pharma KG, ZNS-Forschung/ Molekularbiologie, Binger Str. 173, 55216 Ingelheim a.R., Germany tel: ++49-6132-778460; fax: ++49-6132-774420

e-mail: gillardo@ing.boehringer-ingelheim.com
}

Received 8.6.98; revised 20.8.98; accepted 17.9.98

Edited by J.C. Reed

\begin{abstract}
The effect of bcl-2 gene ablation on epidermal cell death induced by UV-B irradiation was investigated in mice. Exposure of depilated back skin of bcl-2 ${ }^{-/-}$mice to $0.5 \mathrm{~J} /$ $\mathrm{cm}^{2}$ UV-B caused a prolonged increase in the number of epidermal cells showing nuclear DNA fragmentation compared to wild-type littermates. Consistently, skin explants from bcl-2-deficient mice exhibited a higher number of sunburn cells per cm epidermis $(16.6 \pm 2.1$ vs $7.0 \pm 1.5)$ following exposure to $0.1 \mathrm{~J} / \mathrm{cm}^{2} \mathrm{UV}-\mathrm{B}$ in vitro. Furthermore, UV irradiation failed to increase pre-melanosomes in skin explants from mutant animals, and primary menalocyte cultures derived from bcl-2 null mutants were highly susceptible to UV-induced cell death compared to cultures from wild-type littermates. An accelerated reappearance of proliferating cells, showing nuclear immunoreactivity for Ki67 and c-Fos, was observed in the UV-irradiated epidermis of bcl-2-deficient mice. Taken together, these findings suggest that effects of UV radiation on epidermal cell death and cell cycle progression are influenced by survival-promoting Bcl-2.
\end{abstract}

Keywords: ultraviolet radiation; $b c /-2$ gene targeting; DNA damage; apoptosis; proliferation; melanocytes; keratinocytes

Abbreviations: TUNEL, terminal deoxynucleotidyltransferase and biotin-16-dUTP nick end-labeling; UV, ultraviolet

\section{Introduction}

Ultraviolet (UV) radiation in the UV-B or UV-A wavelength range $(290-320 \mathrm{~nm}$ or $320-400 \mathrm{~nm})$ is the major source of cellular damage in the mammalian epidermis. ${ }^{1}$ In epidermal cells UV-B radiation is primarily absorbed by DNA leading to the formation of cyclobutane pyrimidine dimers and pyrimidine $(6-4)$ pyrimidone photoproducts. ${ }^{2-4}$ Exposure to UV light induces formation of apoptotic keratinocytes ('sunburn cells'), which have been defined by morphologic criteria and in situ end-labeling of fragmented DNA. ${ }^{5,6}$ Furthermore, chromatin margination, nuclear fragmentation and oligonucleosomal DNA cleavage have been detected in keratinocytes and melanocytes after UV irradiation in vitro indicating that apoptotic cell death is triggered by genotoxic stress. ${ }^{7,8}$ The function of apoptosis in the UV-exposed skin may be the deletion of aberrant cells that have acquired harmful mutations.

The bcl-2 proto-oncogene product inhibits apoptosis induced by various stimuli in many different cell types. ${ }^{9}$ In the mammalian epidermis distinct $\mathrm{Bcl}-2$ immunoreactivity has been detected in basal keratinocytes and melanocytes, and deregulated expression of $\mathrm{Bcl}-2$ has been linked to malignant transformation. ${ }^{10-12}$ Following cutaneous UV irradiation $\mathrm{Bcl}-2$ expression in keratinocytes is downregulated, whereas overexpression of $\mathrm{Bcl}-2$ in transfected HaCaT keratinocytes confers resistance to UV-B-induced apoptosis. $^{7,13}$ Targeted expression of human $b c /-2$ in the epidermis of transgenic mice prevents apoptotic death of keratinocytes after UV-B exposure strongly suggesting a functional role for $\mathrm{Bcl}-2$ in epidermal cell death after genotoxic stress. ${ }^{14}$ Additionally, three lines of $b c /-2$ deficient mice have been reported which develop similar phenotypic abnormalities after birth, including hair hypopigmentation, suggesting that $b c l-2$ may also be essential for melanocyte function or maintenance under physiological conditions. $^{15-17}$ In the present study, we investigated the effects of $b c /-2$ gene-ablation in mice on UV-induced epidermal cell death in vivo and in vitro.

\section{Results}

Gene ablation of $b c l-2$ increases the rate of epidermal cell death following UV irradiation

Hair pigmentation of $b c l-2^{-/-}$mice was initially indistinguishable from wild-type littermates. At 5-6 weeks postnatally the coats of bcl-2-deficient mice turned gray as has been described previously. ${ }^{15-17}$ Immunostaining of skin sections with a monoclonal antibody that recognizes a membrane antigen of pre-melanosomes $(\mathrm{NKI} / \mathrm{beteb})^{12}$ revealed no significant differences in the number of $\mathrm{NKI} /$ beteb-positive melanocytes between mutant and wild-type mice at 4 weeks of age (data not shown).

No spontaneous cell death was detected by the TUNEL technique in the interfollicular epidermis of both $b c /-2^{-/-}$ and wild-type littermates (Figure 1a,b). To investigate the role of Bcl-2 in genotoxic stress, depilated back skin of 4week-old mice was exposed to $0.5 \mathrm{~J} / \mathrm{cm}^{2}$ of UV-B radiation. Six hours after exposure the number of TUNEL-positive cells per $\mathrm{mm}$ epidermis significantly increased to $53 \pm 8$ in $b c /$-2-deficient mice and to $45 \pm 7$ in wild-types (Figure $1 \mathrm{~b}, \mathrm{e})$. At $24 \mathrm{~h}$ the number of epidermal cells showing DNA fragmentation remained elevated in mutant mice $(57 \pm 5)$, 
whereas the epidermis of wild-type mice was almost completely cleared of TUNEL-positive cells (Figure 1c,f). To exclude an influence of systemic abnormalities (e.g. lymphoid hypoplasia, renal malfunction), which develop postnatally in $\mathrm{bcl}-2^{-/-}$mice,$^{15-17}$ similar experiments were performed using skin explants. The rate of spontaneous epidermal cell death as assessed by hematoxylin-eosin staining tended to increase in skin organ cultures from mutant mice compared to wild-type animals, which however, did not reach significance. More importantly, $24 \mathrm{~h}$ after transient UV-B irradiation $\left(0.1 \mathrm{~J} / \mathrm{cm}^{2}\right)$ in culture the number of epidermal sunburn cells, which are characterized by shrunken size, eosinophilic cytoplasm and a pyknotic nucleus, was significantly higher $(P<0.01$, Mann-Whitney $U$-test) in ex vivo explants from null mutant mice (Figure 2).

Immunostaining of skin sections revealed a twofold increase in the number of $\mathrm{NKI} /$ beteb-positive, dendritic cells in UV-irradiated explants from $b c /-2^{+/+}$mice at $24 \mathrm{~h}$ post-irradiation, whereas the number of $\mathrm{NKI} /$ beteb-immunoreactive, epidermal melanocytes did not change in explants from null mutant animals. Since UV exposure causes both an increase in the number of melanosomes and a proliferation of precursor melanocytes ${ }^{18,19}$ our findings in skin explants could be attributed to either impaired melanogenesis or enhanced radiation sensitivity in melanocytes lacking Bcl-2. Therefore, primary melanocyte cultures were prepared from back skin of 4-week-old animals. No conspicuous differences in cellular morphology or cell number were observed between cultures from mutant and wild-type animals (Figure $3 a, b)$. However, a significant difference in viability became apparent in melanocytes derived from $b c /-2^{-/-}$mice compared to cultures from wild-type littermates following in vitro exposure to UV-B (Figure 3c,d). Twelve hours after irradiation $67 \pm 11 \%$ of the bcl-2-deficient cells showed condensed or fragmented nuclei (Figure $4 b, d$ ), whereas only $12 \pm 5 \%$ of wild-type cells exhibited chromatin condensation (Figure 4a,c)

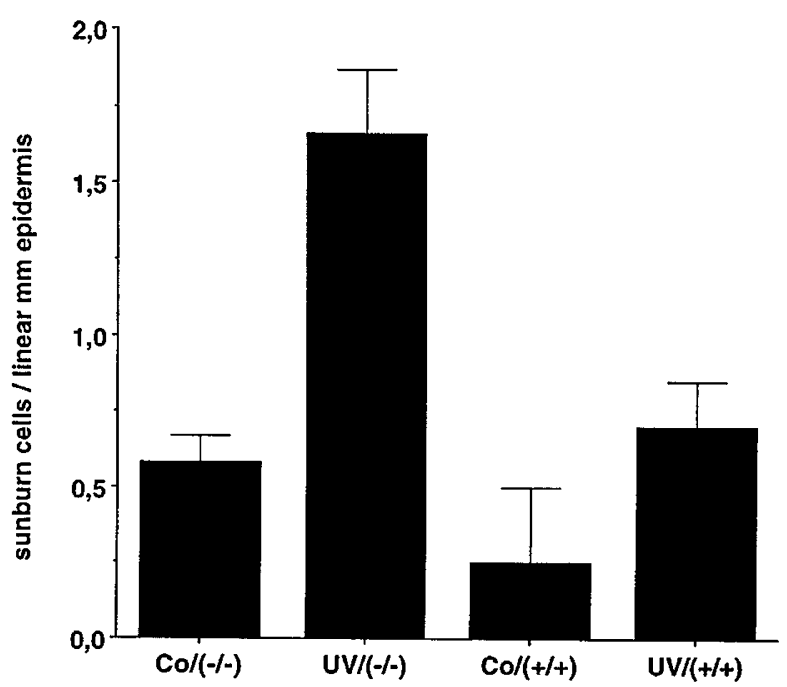

Figure 2 Number of apoptotic keratinocytes ('sunburn cells') in skin explants from $b c l-2^{-1-}$ mice and $b c l-2^{+/+}$littermates (mean \pm S.D., $n=5$ per group). $E x$ vivo skin organ cultures were either sham-treated (Co, Control) or UV-exposed (UV). Twenty-four hours later tissue sections were stained by hematoxylineosin
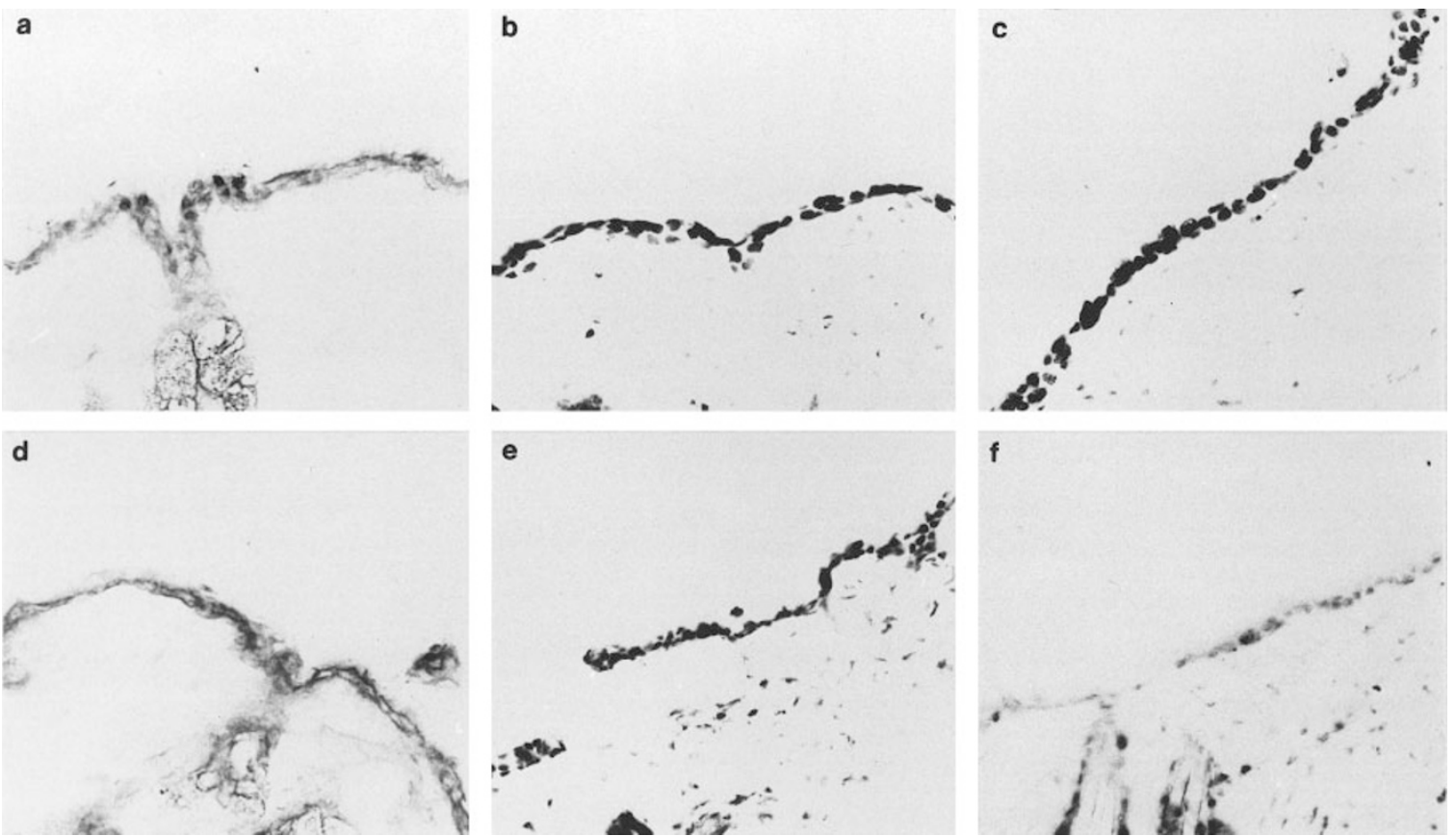

Figure 1 End-labeling of nuclear DNA fragments in sections from back skin of $b c l-2^{-/-}$mice $(\mathbf{a}, \mathbf{b}, \mathbf{c})$ and wild-type littermates, respectively (d,e,f). Mice were either sham-treated $(\mathbf{a}, \mathbf{d})$ or exposed to $0.5 \mathrm{~J} / \mathrm{cm}^{2}$ UV-B radiation and killed after $6 \mathrm{~h}(\mathbf{b}, \mathbf{e})$ or $24 \mathrm{~h}(\mathbf{c}, \mathbf{f})$. Persistent cell death is detectable in the UV-irradiated epidermis of $-1-$ mice 
indicating that $\mathrm{Bcl}-2$ deficiency renders melanocytes more vulnerable to UV-B exposure.

\section{Bcl-2 modulates cell cycle progression after UV exposure}

To investigate the influence of $\mathrm{Bcl}-2$ on epidermal cell proliferation, back skin sections from 4-week-old mice were stained with an antibody against the proliferation-associated antigen Ki-67. In the basal cell layer of the epidermis numerous keratinocytes exhibited nuclear staining for $\mathrm{Ki}-67$ (Figure $5 \mathrm{a}, \mathrm{b}$ ), and cell counts revealed similar numbers of Ki67-positive epidermal cells in null mutant and wild-type mice (Figure 6). Six hours after high-dose UV exposure interfollicular, epidermal Ki-67 labeling slightly declined both in $\mathrm{bcl}$ 2-deficient mice and in wild-types (data not shown). Epidermal

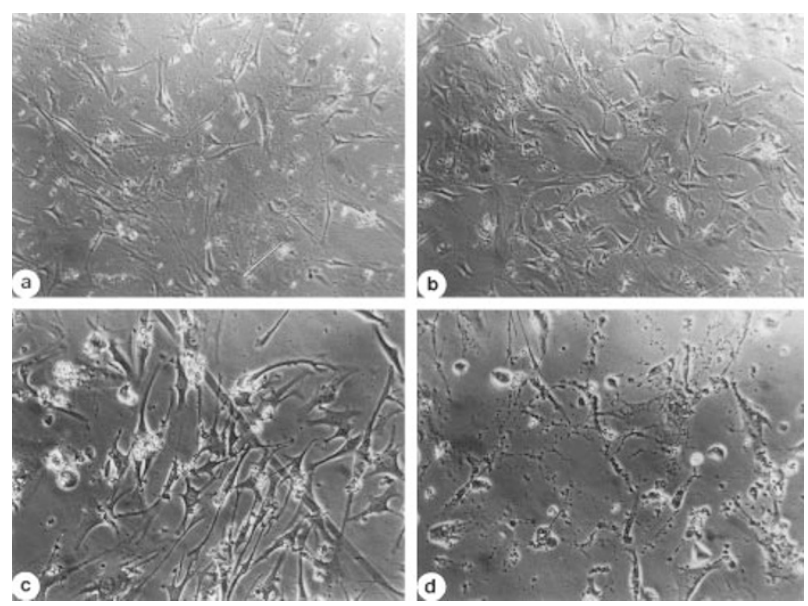

Figure 3 Morphologic appearance of primary melanocyte cultures derived from wild-type $(\mathbf{a}, \mathbf{c})$ or $b c l-2$-deficient mice $(\mathbf{b}, \mathbf{d}) 12 \mathrm{~h}$ after treatment. Cell cultures were either sham-treated $(\mathbf{a}, \mathbf{b})$ or exposed to $0.1 \mathrm{~J} / \mathrm{cm}^{2}$ UV-B $(\mathbf{c}, \mathbf{d})$. Note extensive cell loss in UV-irradiated cultures from mutant mice
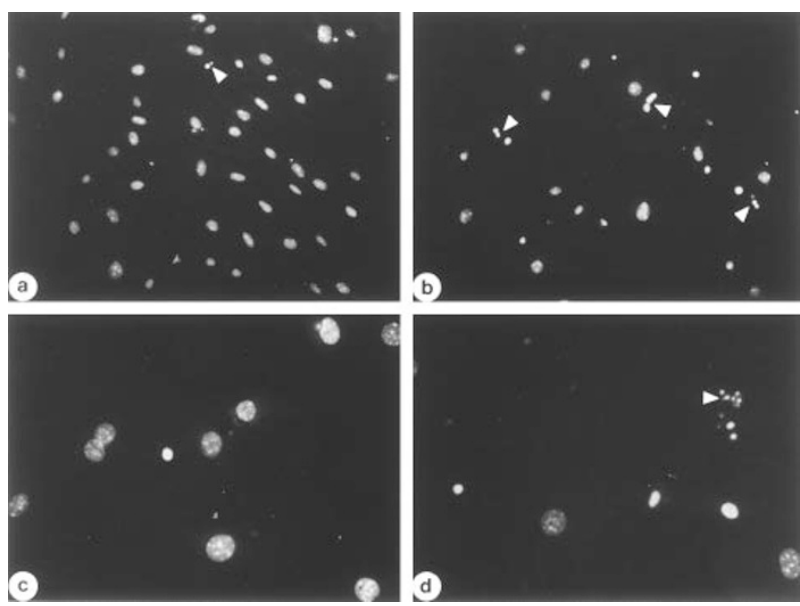

Figure 4 Nuclear morphology of melanocytes derived from wild-type $(\mathbf{a}, \mathbf{c})$ or bcl-2 $2^{-/-}$mice (b,d) $12 \mathrm{~h}$ after UV-B irradiation. Numerous cells showing chromatin condensation and nuclear fragmentation are visible in cultures from null mutant animals (arrowheads) cells in wild-type animals showed prolonged cell cycle arrest as indicated by the significant decrease in Ki-67-positive epidermal cells at $24 \mathrm{~h}$ after irradiation (Figures $5 \mathrm{~d}$ and 6 ). Interestingly, the number of Ki-67-labeled nuclei increased by twofold in the UV-exposed epidermis of $b c /-2^{-/-}$mice already at $24 \mathrm{~h}$ suggesting an accelerated cell cycle re-entry compared to wild-types. Consistent with this notion, coinduction of transcription factor c-Fos was observed exclusively in epidermal cells of null mutant mice at $24 \mathrm{~h}$ postirradiation (data not shown), which has been shown to be necessary for cell cycle progression of skin cells after UV exposure. ${ }^{20-22}$ Double staining of skin sections for Ki-67 and
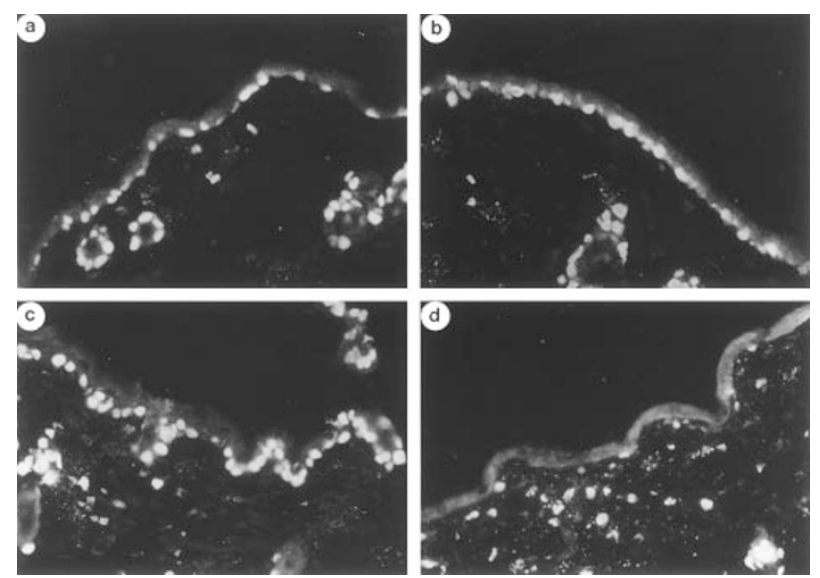

Figure 5 Immunolocalization of the proliferation-associated antigen $\mathrm{Ki}-67$ in dorsal skin from bcl-2-deficient mice (a,c) and wild-type littermates (b,d). Animals were killed $24 \mathrm{~h}$ after sham-treatment $(\mathbf{a}, \mathbf{b})$ or UV-B irradiation $(\mathbf{c}, \mathbf{d})$. Increased proliferation of basal keratinocytes can be observed in the UVexposed epidermis of mutant mice, whereas UV-induced cell cycle arrest is obvious in wild-types

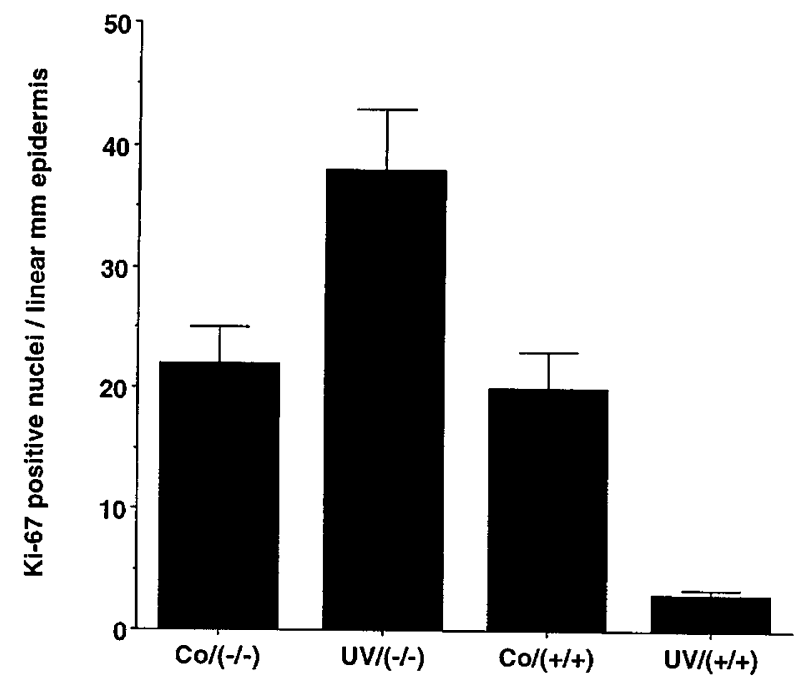

Figure 6 Number of epidermal cells showing nuclear immunoreactivity for the proliferation-associated antigen $\mathrm{Ki}-67$ in skin sections from $b c /-2^{-/-}$mice and from $b c /-2^{+/+}$littermates (mean \pm S.D., $n=5$ animals per group). Animals were killed $24 \mathrm{~h}$ after sham-exposure (Co, Control) or UV-B irradiation (UV) 
DNA fragmentation (TUNEL) revealed lack of co-localization in epidermal cells at $24 \mathrm{~h}$ after UV-B irradiation (Figure 7).

\section{Discussion}

At 4 weeks of age, the rate of spontaneous cell death and histologic appearance was unchanged in the epidermis of bcl2-deficient mice indicating that normal cell turnover and differentiation in keratinocytes proceeds via a $\mathrm{Bcl}-2$ independent mechanism. Furthermore, the number of $\mathrm{NKI} /$ betebimmunoreactive, epidermal melanocytes was similar between wild-type animals and $b c /-2^{-/-}$mice suggesting that development and melanogenesis of epidermal melanocytes is not affected by $b c l-2$ gene ablation. In $b c l-2$ transgenic mice epidermal cell death under physiological conditions is unaltered as well. ${ }^{14}$ On the other hand, the response of epidermal cells to genotoxic stress is influenced by the level of $>b c l-2$ expression. Following UV-B irradiation expression of $b c l-2$ in epidermal keratinocytes and melanocytes is rapidly down-regulated, ${ }^{7,13,23}$ which according to current concepts lowers the threshold for apoptosis. ${ }^{9,24}$ Consistently, a decrease in the number of apoptotic keratinocytes ('sunburn cells') by approximately $50 \%$ has been reported after UV-B exposure of $b c /-2$ transgenic mice or $b c l-2$ overexpressing keratinocyte cultures. ${ }^{7,14}$ In our $b c l-2^{-/-}$mice the number of epidermal cells showing DNA fragmentation did not differ from wild-type littermates at $6 \mathrm{~h}$ after UV-B, whereas at $24 \mathrm{~h}$ the number of TUNEL-positive keratinocytes was much higher in bcl-2-deficient animals. The similar rate of early UV-induced cell death in wild-types and null mutants may be attributed to the higher dose of UV radiation applied in vivo. The second, delayed phase of epidermal cell death however, seems to be sensitive to $b c /-2$ gene ablation and may represent damaged cells which die by apoptotic cell death. Consistently, the number of keratinocytes showing apoptotic morphology ('sunburn cells') was significantly higher in skin explants from bcl-2-deficient mice after low dose UV-B irradiation in vitro. Similarly, high dose UV-B exposure of human cell lines
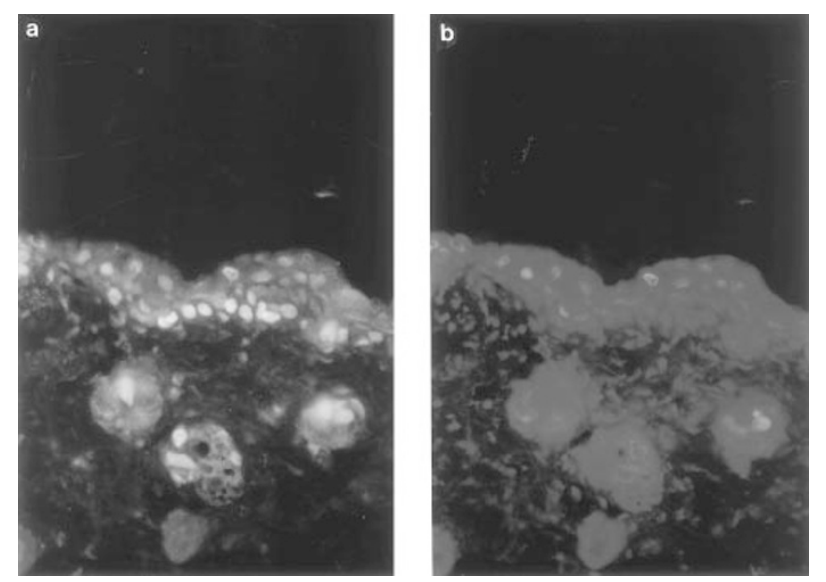

Figure 7 Double staining of skin sections from $b c /$-2-deficient mice for (a) proliferation-associated antigen Ki-67 (green-yellow) and (b) nuclear DNA fragments (TUNEL, red-yellow). Strongly Ki-67 immunopositive cells are concentrated in the basal epidermis, whereas TUNEL-positive cells are detectable in the upper layers. Co-localization is visible in scattered cells only leads to rapid cell death by necrosis, whereas moderate doses evoke apoptotic cell suicide. ${ }^{25}$ However, neither TUNEL-technique nor hematoxylin-eosin staining clearly discriminates between an apoptotic and a necrotic type of cell death. Additionally, UV-B-induced pyrimidine dimers and $(6-4)$ photoproducts are converted into transient singlestrand breaks during nucleotide excision repair, ${ }^{26}$ which may become labeled by TUNEL-technique. Finally, we cannot formally exclude that $b c l-2$ gene ablation affects removal of epidermal sunburn cells which are shed by desquamation or phagocytosed by neighbouring keratinocytes. ${ }^{5,6}$ Time course for the appearance of TUNEL-positive cells and their frequency in our study differs from the findings by, ${ }^{27}$ who showed fewer TUNEL-labeled cells in the UV-irradiated murine epidermis peaking at $24 \mathrm{~h}$. In the latter study, mice were exposed to $0.1 \mathrm{~J} / \mathrm{cm}^{2}$ of UV-B at an irradiance of 11 $\mathrm{J} / \mathrm{m}^{2} \mathrm{xs}$ and DNA fragmentation was detected by direct incorporation of labeled nucleotides, whereas in our study animals were exposed to $0.5 \mathrm{~J} / \mathrm{cm}^{2}$ at $140 \mathrm{~J} / \mathrm{m}^{2} \mathrm{xs}$ and DNA breaks were detected using biotinylated nucleotides and avidin-biotin amplification. Thus, a higher UV dose and/or dose rate may lead to a more rapid apoptotic response and TUNEL with avidin-biotin-based detection may result in a higher sensitivity of detection.

UV exposure of skin organ cultures derived from wildtype mice lead to an increase in the number of $\mathrm{NKI} /$ betebimmunoreactive, epidermal melanocytes which was absent in cultures from mutant mice. These findings could be attributed to either premature cell death or impaired melanin synthesis of melanocytes similar to the postnatal hair hypopigmentation in $b c l-2^{-/-}$mice. ${ }^{15,16,28}$ Primary melanocyte cultures derived from $b c l-2$ null mutants were highly susceptible to UV-induced cell death compared to cultures from wild-type littermates strongly suggesting that $\mathrm{Bcl}-2$ promotes melanocyte survival under stressful conditions. Noteworthy, administration of nerve growth factor has been shown to rescue cultured melanocytes from UVinduced apoptosis, and this rescuing effect was found to be mediated by up-regulation of $\mathrm{Bcl}-2$ levels. ${ }^{8}$

Mammalian cells respond to DNA damage induced by UV radiation with transient arrest in $G_{1}$ and $G_{2}$ to allow for DNA repair before entering the phases of DNA replication and mitosis, respectively. Recovery of DNA synthesis and cell cycle progression appears after a delay of several hours depending on the dose of UV..$^{2-4,29,30}$ Expression of the proliferation-associated nuclear protein $\mathrm{Ki}-67$ is reduced during cell cycle arrest in vitro and is induced in the human epidermis $48 \mathrm{~h}$ after UV-B exposure. ${ }^{30,31}$ In the present study, we found that keratinocytes in the UV-exposed epidermis of $b c /-2^{-/}$mice stopped proliferation with similar kinetics compared to wild-type animals as indicated by the decrease in immunolabeling for proliferationassociated Ki-67 after $6 \mathrm{~h}$. Twenty four hours after UV-B irradiation there was a greater percentage of Ki-67-positive cells in the epidermis of null mutants compared to preirradiation levels which may be due to a synchronization of cell cycling or an increased rate of proliferation. More importantly, Ki-67-immunoreactive epidermal cells were not detected in wild-type animals at $24 \mathrm{~h}$ post-irradiation indicating an accelerated cell cycle re-entry of bcl-2- 
deficient keratinocytes. That UV-irradiated keratinocytes in $b c l-2^{-/-}$mice start cell cycle progression earlier is further indicated by the massive induction of transcription factor cFos at $24 \mathrm{~h}$ which appears to be necessary for cell cycle re-entry of growth-arrested skin cells after UV. ${ }^{20-22}$

There is increasing evidence for an influence of $\mathrm{Bcl}-2$ on cell cycling. T cells from $b c /-2^{-1-}$ mice enter S-phase more rapidly after mitogen stimulation. ${ }^{32}$ Conversely, expression of a $b c /-2$ transgene in lymphocytes and fibroblasts delays cell cycle re-entry after serum stimulation. It has also been shown that proliferation rate under optimal culture conditions and kinetics of withdrawal from the cell cycle following growth factor deprivation are not affected by overexpression of $\mathrm{Bcl}-2^{33-36}$ in agreement with our in vivo findings. Moreover, our study for the first time provides evidence that Bcl-2 influences cell cycle progression also after UVinduced genotoxic stress. It has been hypothesized that Bcl-2 mediated retardation of $\mathrm{G}_{0} / \mathrm{G}_{1}$ to $\mathrm{S}$-phase progression may provide additional time for repair of DNA damage or may inhibit aberrant cell cycle progression, thus contributing to the cell death-preventing activity of $\mathrm{Bcl}-2 .^{33,35} \mathrm{In} \mathrm{bcl-2}$ null mutant mice, Ki-67-immunoreactive epidermal cells reappeared at $24 \mathrm{~h}$ after UV-B exposure, when numerous TUNEL-positive cells were present. It may be speculated that in the absence of $\mathrm{Bcl}-2$ keratinocytes re-enter the cell cycle before UV-induced DNA lesions are completely repaired, which then activates apoptotic cell death. However, we could not detect significant co-localization of nuclear Ki-67-immunoreactivity and DNA fragments at $24 \mathrm{~h}$ post-irradiation in $\mathrm{bcl}-2^{-/-}$keratinocytes speaking against this hypothesis. Unfortunately, cell cycle kinetics have not been investigated in $b c /-2$ overexpressing keratinocytes following UV exposure, ${ }^{7,14}$ however, accelerated cell cycle re-entry of $b c /$-2-deficient keratinocytes occurs too rapid to be attributed solely to indirect homeostatic feedback mechanisms that compensate for increased UV-induced cell loss. ${ }^{29}$ This may be deduced from recent findings in UV-irradiated $b c /-x_{s}$ transgenic mice, where increased epidermal cell death leads to a dramatic reduction of keratinocytes at $24 \mathrm{~h}^{37}$

\section{Materials and Methods}

\section{Animals}

The targeted disruption of the bcl-2 gene and the generation of the knockout mice has been described previously. ${ }^{17}$ Litters produced by matings between heterozygous mice were genotyped by Southern blot analysis of genomic DNA extracted from pieces of tail using standard molecular biology techniques.

\section{Tissue and cell culture}

About $4 \mathrm{~mm}^{2}$ explants of depilated mouse back skin were placed on sterile gauze and immersed in RPMI 1640 medium (Gibco). Primary melanocyte cultures were prepared from epidermal sheets of back skin as described. ${ }^{38}$ Melanocytes were cultured on glass coverslips in 24well plates using melanocyte growth medium supplemented with $0.4 \%$ bovine pituitary extract, $1 \mathrm{ng} / \mathrm{ml}$ basic fibroblast growth factor, $5 \mu \mathrm{g} / \mathrm{ml}$ insulin, $0.5 \mu \mathrm{g} / \mathrm{ml}$ hydrocortisone and $10 \mathrm{ng} / \mathrm{ml}$ phorbol myristate acetate.

\section{Ultraviolet irradiation}

Tissue and cell cultures ( $n=6$ each) were irradiated through the petri dish plastic cover at $0.1 \mathrm{~J} / \mathrm{cm}^{2} \mathrm{UV}-\mathrm{B}$ which is sufficient for induction of apoptotic cell death. ${ }^{7,8,14}$ During exposure culture medium was replaced with phosphate-buffered saline (PBS) to avoid formation of cytotoxic photoproducts. Sham-irradiated cultures were processed in parallel but covered with aluminium foil. Back skin of mice $(n=5$ per group, 4 weeks of age) was depilated using depilatory cream and received a single exposure of $0.5 \mathrm{~J} / \mathrm{cm}^{2}$ UV-B. This dose has been shown to induce inflammation and cell death in the murine epidermis. $^{13}$

\section{Immunocytochemistry}

After fixation in 4\% paraformaldehyde in PBS tissue sections (15 $\mu \mathrm{m})$ were incubated overnight at $4{ }^{\circ} \mathrm{C}$ in one of the following antisera: (i) a monoclonal mouse anti-melanoma-associated antigen antiserum (clone NKI/beteb, 1:50, Monosan), (ii) a polyclonal rabbit anti-Ki-67 antiserum (1:50, Dianova), or (iii) a polyclonal rabbit anti-c-Fos antiserum (1:1000, generously donated by $R$. Bravo). Sections were subsequently incubated in biotinylated secondary antibody and antibody binding was localized either by avidin-biotin-peroxidase technique (Vector) or by streptavidin-cychrome-3 (Sigma). For quantitative analysis, positive cells in the interfollicular epidermis were counted in five different microscopic fields per section with the investigator being unaware of treatment and the mean counts per linear millimeter of epidermis were calculated.

\section{Cell death assay}

Degenerating cells were identified in tissue sections by in situ endlabeling of nuclear DNA fragments using terminal deoxynucleotidyltransferase and biotin16-dUTP (TUNEL) or by standard histological detection of sunburn cells after staining with hematoxylin and eosin. For co-localization analysis, sections were stained by the TUNEL technique followed by immunolabeling for Ki-67 as described above. Incorporated biotin-dUTP was detected by streptavidin-cychrome-3 and antibody binding was localized by FITC-conjugated secondary antibody. In cell culture, nuclear morphology was analyzed after staining with the chromatin-dye HOECHST $33342(5 \mu \mathrm{g} / \mathrm{ml})$. The number of homogenously stained nuclei versus condensed/fragmented nuclei was determined in five representative microscopical fields per well.

\section{Acknowledgements}

The authors would like to thank S. Amato, S. Kief and P. Lorenz for skillful technical assistance.

\section{References}

1. Matsui MS and DeLeoVA (1991) Longwave ultraviolet radiation and promotion of skin cancer. Cancer Cells $3: 8-12$

2. Gewirtz DA (1993) DNA damage, gene expression, growth arrest and cell death. Oncology Res., 5: 397-408

3. Tornaletti S and Pfeifer GP (1996) UV damage and repair mechanisms in mammalian cells. Bioessays 18: 221-228

4. Tyrrell RM (1996) Activation of mammalian gene expression by the UV component of sunlight from models to reality. Bioessays 18: 139-148

5. Young AR (1986) The sunburn cell. Photodermatol. 4: 127-134

6. Danno K and Horio T (1987) Sunburn cell: factors involved in its formation. Photochem. Photobiol. 45: 683-690 
7. Haake AR and Polakowska RR(1995) UV-induced apoptosis in skin equivalents: inhibition by phorbol ester and Bcl-2 overexpression. Cell Death Differ. 2: 183193

8. Zhai S, Yaar M, Doyle SM and Gilchrest B (1996) Nerve growth factor rescues pigment cells from ultraviolet-induced apoptosis by upregulating $\mathrm{Bcl}-2$ levels. Exp. Cell Res. 224: $335-343$

9. Reed JC (1997) Double identity for proteins of the Bcl-2 family. Nature 387: $773-$ 776

10. Krajewski S, Krajewska M, Shabaik A, Miyashita T, Wang HG and Reed JC (1994) Immunohistochemical determination of in vivo distribution of Bax, a dominant inhibitor of Bcl-2. Am. J. Pathol. 145: 1323-1336

11. Marthinhuss J, Lawrence $L$ and Seiberg M (1995) Apoptosis in Pam212, an epidermal keratinocyte cell line: a possible role for bcl-2 in epidermal differentiation. Cell Growth Differ. 6: 239-250

12. Plettenberg A, Ballaun C, Pammer J, Mildner M, Strunk D, Weninger W and Tschachler E (1995) Human melanocytes and melanoma cells constitutively express the Bcl-2 proto-oncogene in situ and in cell culture. Am. J. Pathol. 146: $651-659$

13. Gillardon F, Eschenfelder C, Uhlmann E, Hartschuh W and Zimmermann M (1994) Differential regulation of c-fos, fosB, c-jun, junB, bcl-2 and bax expression in rat skin following single or chronic ultraviolet irradiation and in vivo modulation by antisense oligodeoxynucleotide superfusion. Oncogene 9: 3219-3225

14. Rodriguez-Villanueva J, Greenhalgh D, Wang XJ, Bundman D, Cho S Delehedde M, Roop D and McDonnell TJ (1998) Human keratin-1.bcl-2 transgenic mice aberrantly express keratin 6 , exhibit reduced sensitivity to keratinocyte cell death induction, and are susceptible to skin tumor formation. Oncogene 16: 853-863

15. Veis DJ, Sorenson CM, Shutter JR and Korsmeyer SJ (1993) Bcl-2-deficient mice demonstrate fulminant lymphoid apoptosis, polycystic kidneys, and hypopigmented hair. Cell 75: 229-240

16. Nakayama K, Nakayama KI, Negishi I, Kuida K, Sawa H and Loh DY (1994) Targeted disruption of $\mathrm{Bcl}-2 \alpha \beta$ in mice: occurrence of gray hair, polycystic kidney disease, and lymphocytopenia. Proc. Natl. Acad. Sci. USA 91: 3700-3704

17. Michaelidis TM, Sendtner M, Cooper JD, Airaksinen MS, Holtmann B, Meyer M and Thoenen $\mathrm{H}$ (1996) Inactivation of bcl-2 results in progressive degeneration of motoneurons, sympathetic and sensory neurons during early postnata development. Neuron 17: 75-89

18. Jimbow $\mathrm{K}$ and Uesugi $\mathrm{T}$ (1982) New melanogenesis and photobiological processes in activation and proliferation of precursor melanocytes after UVexposure: ultrastructural differentiation of precursor melanocytes from Langerhans cells. J. Invest. Dermatol. 78: 108-115

19. Ryckmanns F, Schmoeckel C, Plewig G and Braun-Falco O (1987) Early persistent UVA-pigmentation: ultrastructural and morphometric analyses. Arch. Dermatol. Res. 279: 173-179

20. Gillardon F, Moll I and UhImann E (1995) Inhibition of c-Fos expression in the UVirradiated epidermis by topical application of antisense oligodeoxynucleotides suppresses activation of proliferating cell nuclear antigen. Carcinogenesis 16 : $1853-1856$

21. Haas and Kaina B (1995) c-Fos is involved in the cellular defense against the genotoxic effect of UV radiation. Carcinogenesis 16: 985-991
22. Schreiber M, Baumann B, Cotten M, Angel Pa and Wagner EF (1995) Fos is an essential component of the mammalian UV response. EMBO J. 14:5338-5349

23. Bayerl C, Taake S, Moll I and Jung EG (1995) Characterization of sunburn cells after exposure to ultraviolet light. Photodermatol. Photoimmunol. Photomed. 11: $149-154$

24. Oltvai ZN, Milliman CL and Korsmeyer SJ (1993) Bcl-2 heterodimerizes in vivo with a conserved homolog, Bax, that accelerates programmed cell death. Cell 74: 609-619

25. Martin SJ and Cotter TG (1991) Ultraviolet B irradiation of human leukemia HL-60 cells in vitro induces apoptosis. Int. J. Radiat. Biol. 59: 1001-1016

26. Kinley JS, Brunborg G, Moan J and Young AR (1995) Detection of UVR-induced DNA damage in mouse epidermis in vivo using alkaline elution. Photochem. Photobiol. 61: 149-158

27. Ziegler A, Jonason AS, Leffell DJ, Simon JA, Sharma HW, Kimmelman J, Remington L, Jacks T and Brash DE (1994) Sunburn and the onset of skin cancer. Nature 372: $773-776$

28. Yamamura K, Kamada S, Ito S, Nakagawa K, Ichihashi M and Tsujimoto Y (1996) Accelerated disappearance of melanocytes in bcl-2-deficient mice. Cancer Res. 56: $3546-3550$

29. Epstein JH, Fukuyama K and Fye K (1970) Effects of ultraviolet radiation on the mitotic cycle and DNA, RNA and protein synthesis in mammalian epidermis in vivo. Photochem. Photobiol. 12: 57-65

30. Ueda M, Ahmed NU, Bito T, Nagano T and Ichihashi M (1996) The expression of retinoblastoma protein in epidermis is induced by ultraviolet $\mathrm{B}$ exposure. $\mathrm{Br}$. J. Dermatol. 135: 406-411

31. JakobisiakM, Bruno S, Skierski JS and Darzynkiewicz (1991) Cell cycle-specific effects of lovastatin. Proc. Natl. Acad. Sci. USA 88: 3628-3632

32. Linette GP, Li Y, Roth K and Korsmeyer SJ (1996) Cross talk between cell death and cell cycle progression: Bcl-2 regulates NFAT-mediated activation. Proc. Natl. Acad. Sci. USA 93: 9545-9552

33. Borner C (1996) Diminished cell proliferation associated with the deathprotective activity of Bcl-2. J. Biol. Chem. 271: 12695-12698

34. O'Reilly LA, Huang DCS and Strasser A (1996) The cell death inhibitor Bcl-2 and its homologues influence control of cell cycle entry. EMBO J. 15: 6979-6990

35. Mazel S, Burtrum D and Petrie HT (1996) Regulation of cell division cycle progression and bcl-2 expression: a potential mechanism for inhibition of programmed cell death. J. Exp. Med. 183: 2219-2226

36. Huang DCS, O'Reilly LA, Strasser A and Cory S (1997) The anti-apoptotic function of Bcl-2 can be separated from its inhibitory effect on cell cycle entry. EMBO J. 16: $4628-4638$

37. Pena JC, Fuchs E and Thompson CB (1997) Bcl-x expression influences keratinocyte cell survival but not terminal differentiation. Cell Growth Diff. 8: $619-629$

38. Prunieras M, Delescluse $C$ and Regnier M (1976) The culture of skin. A review of theories and experimental methods. J. Invest. Dermatol. 67: 58-65 